\title{
Correlates of Mycobacterium tuberculosis infection in a prison population
}

\author{
S. Carbonara*, S. Babudieri", B. Longo", G. Starnini ${ }^{+}$, R. Monarca ${ }^{+}$, B. Brunetti ${ }^{\S}$, \\ M. Andreoni ${ }^{\dagger}$, G. Pastore*, V. De Marco**, G. Rezza" and GLIP (Gruppo di \\ Lavoro Infettivologi Penitenziari)
}

ABSTRACT: Prisons represent a crucial setting for tuberculosis control. Currently, there is scarce information concerning Mycobacterium tuberculosis (MT) infection in European prisons, and no data are available for Italy. This study aims to describe the prevalence and correlates of MT infection in an Italian prison population.

In this multicentre cross-sectional study, 1,247 inmates from nine prisons were recruited and asked to undergo questioning regarding socio-economic and demographic variables, tuberculin skin testing (TST), chest radiographs and testing for HIV, hepatitis B and hepatitis C virus infection.

TST was positive in $\mathbf{1 7 . 9 \%}$ of the 448 evaluable subjects. With multivariate logistic regression (performed among male inmates), MT infection was correlated with age (adjusted odds ratio (OR) 4.12 for inmates aged $31-40 \mathrm{yrs} ; 3.78$ for those aged $>40 \mathrm{yrs}$ ), being foreign-born (OR=4.9), education $\leqslant 5$ yrs $(O R=1.88)$ and length of detention (increased risk per yr: $11 \%)$.

As with elsewhere in the world, the prison system in Italy features a population with an increased rate of Mycobacterium tuberculosis infection and at-risk rate for Mycobacterium tuberculosis transmission. Improved tuberculosis surveillance and control measures are deemed necessary in correctional facilities nationwide, especially for subjects with the above risk factors and those who are HIV infected, in whom the tuberculin skin testing can be misleading. The screening of entrants is particularly important to avoid undiagnosed smear-positive tuberculosis cases.

KEYWORDS: Inmates, Mycobacterium tuberculosis, prisons, tuberculin skin testing, tuberculosis

$\mathbf{P}$ risons represent a crucial setting for tuberculosis (TB) control. Worldwide, 10-100-times higher rates have been reported for TB in correctional systems than in the local civilian populations [1], and outbreaks have also been documented [2-5]. Regardless of the pattern of $\mathrm{TB}$ spread among prisoners, i.e. endemic cases versus outbreaks, TB has repeatedly been shown to also involve the prison staff [6-9] and the surrounding community $[2,10,11]$, to the extent that the World Health Organization recently stated that "prisons act as a reservoir for $\mathrm{TB}$, pumping the disease into the civilian community through staff, visitors and inadequatelytreated released inmates" [12]. Moreover, a high rate of multidrug-resistant $\mathrm{TB}$ (up to $32 \%$ ) has been observed in several jail settings, both in industrialised and developing countries $[1,5,13-$ 16]. Lastly, the case-fatality rate among TB cases can reach $24 \%$ and, in some prisons, TB accounts for $50 \%$ of the overall prison deaths [17].

The causes for this overwhelming impact of TB in correctional institutions are multiple and include the following [1, 18-22]: 1) overcrowding, together with a high concentration of at-risk subjects for Mycobacterium tuberculosis (MT) infection and disease (e.g. socio-economically disadvantaged, HIV infected, drug addicts, immigrants from countries with high TB prevalence); 2) poor ventilation and unhygienic conditions; 3) high mobility of inmates within the same facility and among different facilities; and 4) inadequacy of TB control measures.

Thus far, only a few reports have investigated the prevalence and characteristics of MT infection in correctional settings in the following countries: USA [23-28], Pakistan [29] and only Spain [30, 31] among the European countries. Nevertheless, several elements suggest that MT infection is present in high levels in Italian prisons. First, even though no register of $\mathrm{TB}$ cases in the national correctional system exists, the latest available survey conducted (1994) showed a high TB incidence: 290 cases $\cdot 100,000^{-1} \cdot \mathrm{yr}^{-1}$, that is, 31.6-times greater than that reported among the Italian civilian population in the same year [32].
AFFILIATIONS

${ }^{\star}$ Clinic of Infectious Diseases,

University of Bari,

**Bari Jail, Bari, and

\#Institute of Infectious Diseases,

University of Sassari, Sassari, and

-Dept of Infectious Parasitic and

Immune-mediated Diseases, The

National Institute of Health,

${ }^{\S}$ Dept of Correctional Facilities,

Ministry of Justice,

${ }^{f}$ Dept of Public Health, Tor Vergata

University, Rome, and

${ }^{+}$Infectious Diseases Unit, Belcolle

Hospital, Viterbo, Italy.

CORRESPONDENCE

S. Carbonara

Clinica Malattie Infettive

Università di Bari

Piazza G. Cesare 11

70124 Bari

Italy

Fax: 390805478333

E-mail: s_carbonara@yahoo.it

Received:

August 232004

Accepted after revision:

January 112005

European Respiratory Journal

Print ISSN 0903-1936

Online ISSN 1399-3003 
Furthermore, in Italy, drug addicts, who represent a high proportion of prisoners [33], have always constituted the largest risk group for HIV infection [34], which is a wellknown risk factor for both MT infection and disease [35]. Moreover, Italy is geographically close to poorly developed countries in the Mediterranean area, such as Eastern Europe and North-African countries, well known for their high TB prevalence, large migrant populations (both legal and illegal) and high imprisonment rates in Italian prisons.

Herein, the results of a study to assess the prevalence and correlates of MT infection in an Italian prison population are reported.

\section{METHODS}

A multicentre cross-sectional study was conducted, in cooperation with the Dept of Correctional Facilities (Rome, Italy), in nine prisons: two in northern Italy, two in central Italy, two in the south and three in the principal islands (Sicily and Sardinia). At the time of the survey, these prisons, which participated in the study on a voluntary basis, were hosting 4,251 inmates, i.e. $8.0 \%$ of the total population imprisoned in Italy in that same period.

The inmates were recruited between November 1, 2001 and February 20, 2002, by infectious-disease specialists acting as prison consultants, each of whom was asked to enrol $\geqslant 10 \%$ of the total prison population. Enrolment in the study was proposed to all inmates in the smaller prisons and only to those in certain wards in the larger facilities. Written informed consent was provided by all participating inmates, who were administered, by a physician or a professional nurse designated by each institution, an anonymous, standardised questionnaire developed for this study. The information collected included demographic data (i.e. age, sex, place of birth, time of immigration to Italy), behavioural data (i.e. history of illicit drugs or alcohol use), social data (i.e. living conditions before arrest, educational level) and history of imprisonment (i.e. current and previous periods of detention).

Participants were also offered tuberculin skin testing (TST) using the Mantoux method, i.e. an intradermal injection into the volar surface of forearm of 5 UI of tuberculin purified protein derivative (PPD; Biocine-test PPD; Chiron Vaccines, Oxford, UK), bio-equivalent to 5 tuberculin units of PPD-S per test dose $(0.1 \mathrm{~mL})$. The test was interpreted after $72 \mathrm{~h}$ and the diameter of the induration reaction was recorded in $\mathrm{mm}$. A chest radiograph was requested for individuals showing a reaction $\geqslant 5 \mathrm{~mm}$. After the complete series of tests, inmates were defined as "infected" or "noninfected" by MT, according to the Centers for Disease Control and Prevention criteria for interpretation of TST results [36]. Briefly, the test was considered positive if an induration area $\geqslant 5 \mathrm{~mm}$ was detected among individuals with HIV infection, in those having had recent contact with $\mathrm{TB}$ patients and in those whose chest radiographs showed fibrotic changes consistent with prior TB. In the remaining inmates, the test was considered positive if an induration area $\geqslant 10 \mathrm{~mm}$ was recorded. Lastly, the participants underwent testing for HIV, hepatitis B (HBV) and C viruses (HCV), as well as the determination of alanine aminotransferase levels. Those with HIV infection were also assessed for HIV risk factors, staging of HIV disease, CD4+ lymphocyte count and HIV plasma viral load. A progressive non-nominal identity code was used to link the questionnaire and serum samples of the same subject.

Data were recorded in a computerised database. The odds ratios (OR) and 95\% confidence intervals (CI) were calculated to correlate positivity to TST with demographic or behavioural variables. Independent associations were evaluated by calculating the adjusted OR with a logistic regression analysis.

\section{RESULTS}

Overall, 1,247 inmates entered the study and underwent collection of questionnaire data. Of these, 448 (36\%) subjects entered the analysis, whereas 799 (64\%) individuals were excluded because of TST refusal, missed testing/test reading, missed chest radiograph, prison release or interfacility transfer. In particular, 89 out of 799 (11\%) HIV-negative subjects had TST with a reaction ranging $5-9 \mathrm{~mm}$, but did not have chest radiographs. When comparing the characteristics of the study participants with those of the excluded prisoners, the two groups were shown to differ slightly in age (median age $36 \mathrm{yrs}$ in the participants (interquartile range (IQR) 30-45) versus 35 yrs in the excluded group (IQR 29-43); p<0.05), sex $(18.3 \%$ females versus $6.6 \%$, respectively; $\mathrm{p}<0.05)$ and origin $(26.8 \%$ foreign-born versus $17.6 \%$; $<0.05$ ); the proportion of $\mathrm{HIV}$ infected subjects and intravenous drug users (IDUs) was similar in the two groups $(7.9 \%$ versus $6.7 \%, p=0.46$, and $27.5 \%$ versus $31.1 \%, \mathrm{p}=0.15$, respectively).

Among the 448 inmates subjected to analysis, 338 underwent HIV testing, with 27 (7.9\%) diagnosed as HIV infected, in whom the median CD4+ lymphocyte count was 314 cells $\cdot \mu \mathrm{L}^{-1}$ (IQR 197-550); HIV viral load was undetectable in four out of 27 inmates and equal to a median of 19,000 copies $\cdot \mathrm{mL}^{-1}$ (IQR $856-100,000)$ in the remaining. TST was positive in 80 out of $448(17.9 \%)$ inmates (95\% CI 14.3-21.4), according to the previously mentioned criteria. Two subjects had active, culture-confirmed $\mathrm{TB}$, including one Italian-born patient with pulmonary TB and one HIV-infected subject from Tunisia with both pulmonary and renal TB.

The results of the univariate analysis regarding the association of the patient characteristics with TST are shown in table 1. In particular, MT infection was associated with male sex and showed a sharp increase in disease risk after 30 yrs of age. The median (IQR) age of MT infected and noninfected inmates was 39 (34-47) and 35 yrs $(30-44.5 ; \mathrm{p}<0.001)$, respectively. When compared with Italian-born inmates, foreign prisoners were 3.6-times more likely to be positive with TST. The specific ORs for MT infection according to geographic area of birth are presented in tables 2 and 3. Among foreign inmates, no association was found between TST results and time of arrival in Italy, when using time as a continuous variable or using a cut-off of either 24 or 36 months. MT infection was also associated with education duration of $\leqslant 5 \mathrm{yrs}$, a living condition of $\geqslant 3$ persons per room before imprisonment, and a current detention $>2$ yrs. In fact, the median (IQR) time period from the last imprisonment was 2.5 yrs (0.9-4.5) for MT-infected inmates and 1.6 yrs (0.5-33) for noninfected individuals (rank sum test, $\mathrm{p}=0.01$ ). TST positivity was less common among subjects with HIV infection, even though this difference was statistically weak $(p=0.08)$. A MT and HIV co-infection was detected in $0.6 \%$ of all 338 prisoners tested 


\begin{tabular}{|c|c|c|c|c|}
\hline TABLE 1 & \multicolumn{4}{|c|}{$\begin{array}{l}\text { Risk factors for tuberculin skin testing positivity } \\
\text { (TST+) among } 448 \text { inmates from nine Italian } \\
\text { prisons }\end{array}$} \\
\hline Variables & & TST+ & OR $(95 \% \mathrm{Cl})$ & p-value \\
\hline \multicolumn{5}{|l|}{ Sex } \\
\hline Female & & $1 / 82(1.2)$ & 1 & \\
\hline Male & & $79 / 366(21.6)$ & $22.3(3.7-902.3)$ & $<0.01$ \\
\hline \multicolumn{5}{|l|}{ Age yrs } \\
\hline$\leqslant 30$ & & $8 / 116(6.9)$ & 1 & \\
\hline $31-40$ & & 38/162 (23.4) & $4.1(1.8-9.2)$ & 0.001 \\
\hline$>40$ & & $34 / 170(20.0)$ & $3.3(1.5-7.6)$ & 0.003 \\
\hline \multicolumn{5}{|l|}{ Origin } \\
\hline Italy & & 40/328 (12.2) & 1 & \\
\hline Foreign & & 40/120 (33.3) & $3.6(2.1-6.1)$ & $<0.001$ \\
\hline \multicolumn{5}{|c|}{ Time from arrival in Italy } \\
\hline$\leqslant 36$ month & & 6/23 (26.1) & 1 & \\
\hline$>36$ month & & 32/85 (37.6) & $1.7(0.5-5.8)$ & NS \\
\hline \multicolumn{5}{|c|}{ Educational level yrs } \\
\hline$>5$ & & 42/281 (14.95) & 1 & \\
\hline$\leqslant 5$ & & 38/167 (22.75) & $1.6(0.99-2.81)$ & 0.04 \\
\hline \multicolumn{5}{|c|}{ Living conditions $\#$} \\
\hline$<3$ persons & room $^{-1}$ & 9/101 (8.9) & 1 & \\
\hline$\geqslant 3$ persons & room $^{-1}$ & $71 / 347(20.4)$ & $2.6(1.2-6.2)$ & 0.007 \\
\hline \multicolumn{5}{|c|}{ Previous imprisonments } \\
\hline No & & 2/33 (6.0) & 1 & \\
\hline Yes & & 58/291 (19.9) & $3.8(0.9-34.1)$ & 0.058 \\
\hline \multicolumn{5}{|c|}{$\begin{array}{l}\text { Length of current imprisonment } \\
\text { yrs }\end{array}$} \\
\hline$\leqslant 2$ & & 33/237 (13.9) & 1 & \\
\hline$>2-\leqslant 4$ & & 23/98 (23.5) & $1.89(1.04-3.4)$ & 0.035 \\
\hline$>4-\leqslant 6$ & & 12/44 (22.2) & $2.31(1.08-4.9)$ & 0.030 \\
\hline$>6$ & & $12 / 49(24.5)$ & $2.00(0.94-4.2)$ & 0.068 \\
\hline \multicolumn{5}{|c|}{ Intravenous drug addiction } \\
\hline No & & 60/325 (18.4) & 1 & \\
\hline Yes & & 20/123 (16.2) & $0.8(0.4-1.5)$ & NS \\
\hline \multicolumn{5}{|c|}{ Alcohol abuse } \\
\hline No & & 58/336 (17.5) & 1 & \\
\hline Yes & & 21/112 (18.7) & $1.08(0.6-1.9)$ & NS \\
\hline \multicolumn{5}{|c|}{ Anti-HCV+ and/or HBsAg+ } \\
\hline No & & 41/190 (21.6) & 1 & \\
\hline Yes & & 19/100 (19.0) & $0.8(0.4-1.6)$ & NS \\
\hline \multicolumn{5}{|l|}{ Hepatitis } \\
\hline $\mathrm{ALT}<60 \mathrm{U}$ & & 29/192 (15.1) & 1 & \\
\hline$A L T \geqslant 60 U$ & & $10 / 64(1.5)$ & $1.04(0.4-2.3)$ & NS \\
\hline \multicolumn{5}{|c|}{ Anti-HIV+ } \\
\hline No & & 69/311 (22.2) & 1 & \\
\hline Yes & & 2/27 (7.4) & $0.28(0.03-1.17)$ & 0.08 \\
\hline
\end{tabular}

Data are presented as $n / N(\%)$, unless otherwise stated. OR: odds ratio; $\mathrm{Cl}$ : confidence interval; $\mathrm{HCV}$ : hepatitis $\mathrm{C}$ virus; $\mathrm{HBs} A g$ : hepatitis $B$ surface antigen; ALT: alanine aminotransferase; NS: nonsignificant. \#: living conditions were based on the ratio between the number of housemates and number of rooms where the inmate lived before imprisonment.

and in $1.1 \%$ of HIV-tested IDUs. A positive TST was not correlated with history of intravenous drug or alcohol use, nor to $\mathrm{HCV}$ and/or HBV infection or hepatitis.
TABLE 2 Risk for tuberculin skin testing positivity (TST+) according to geographical area of birth compared with Italian-born

\begin{tabular}{lrcc} 
Area & \multicolumn{1}{c}{ TST+ } & OR (95\% Cl) & p-value \\
\hline Italy & $40 / 328(12.20)$ & 1 & \\
Western Europe & $3 / 16(18.75)$ & $1.66(0.45-6.08)$ & NS \\
Eastern Europe & $11 / 29(37.93)$ & $4.40(1.93-9.98)$ & $<0.001$ \\
South America & $8 / 25(32.00)$ & $3.38(1.37-8.35)$ & 0.008 \\
Africa & $16 / 43(37.21)$ & $4.26(2.11-8.60)$ & $<0.001$ \\
Others & $2 / 7(28.57)$ & $2.88(0.54-15.34)$ & NS \\
\hline
\end{tabular}

Data are presented as $\mathrm{n} / \mathrm{N}(\%)$, unless otherwise stated. OR: odds ratio; $\mathrm{Cl}$ : confidence interval; NS: nonsignificant.

TABLE 3 Risk for tuberculin skin testing positivity (TST+) according to Italian area of birth

\begin{tabular}{lcccc} 
Area & TST+ & OR (95\% Cl) & p-value TB incidence \\
\hline Italy & & & & \\
$\quad$ North & $1 / 21(4.76)$ & $0.24(0.03-1.89)$ & 0.17 & 69.93 \\
$\quad$ Centre & $4 / 32(12.50)$ & $0.69(0.22-2.14)$ & 0.53 & 22.05 \\
$\quad$ South & $29 / 171(16.96)$ & 1 & & 32.04 \\
$\quad$ Main Islands & $6 / 103(5.83)$ & $0.30(0.12-0.75)$ & 0.011 & 10.00 \\
\hline
\end{tabular}

Data are presented as $\mathrm{n} / \mathrm{N}(\%)$, unless otherwise stated. OR: odds ratio; $\mathrm{Cl}$ : confidence interval; TB: tuberculosis. \#: per 100,000, based on TB cases notified in 2002 among general population; ${ }^{\top}$ : Sicily, Sardinia.

The variables significantly associated with TST positivity at univariate analysis were included in a logistic regression model (table 4). However, this multivariate analysis was performed only on the male population due to the limited number of females and to the presence of an interaction between sex and previous imprisonments. An age $>30 \mathrm{yrs}$, foreign birth and length of current detention were independently associated with MT infection. A slightly significant association was found for an educational level $\leqslant 5$ yrs.

TABLE 4 Multiple logistic regression model to identify independently related determinants for positive tuberculin skin test in male inmates

\begin{tabular}{llr} 
Characteristics & OR $(\mathbf{9 5} \% \mathbf{~ C l )}$ & p-value \\
\hline Age $\mathbf{3 1 - 4 0}$ yrs & $4.12(1.53-11.09)$ & 0.005 \\
Age $>\mathbf{4 0}$ yrs & $3.78(1.35-10.60)$ & 0.011 \\
Foreign-born & $4.89(2.40-9.97)$ & $<0.001$ \\
Education $\leqslant \mathbf{5}$ yrs & $1.88(0.96-3.66)$ & 0.063 \\
Living conditions $\geqslant \mathbf{3}$ persons $\cdot$ room $^{-1}$ & $1.65(0.50-5.51)$ & 0.409 \\
Previous imprisonments & $5.67(0.67-47.50)$ & 0.109 \\
Length of stay in prison yrs & $1.11(1.01-1.22)$ & 0.030 \\
\hline
\end{tabular}

OR: odds ratio; $\mathrm{Cl}$ : confidence interval. 


\section{DISCUSSION}

Prisons are universally recognised as crucial settings for the prevention and control of MT infection [1, 22, 37], thereby also influencing the MT spread among the general population [1, $21,22,27,37]$. To the current authors' knowledge, this is the first report investigating MT infection in a prison population within the Italian correctional system. To date, only two studies published in Spain have investigated this problem among European countries [30, 31].

A major limitation of the current study was the low proportion of inmates $(36 \%)$ who had a fully determined TST, which was required for eligibility into the study. The diverse distribution of several variables (i.e. age, sex and area of origin) between the subjects who entered the study and those excluded might have influenced the estimation of MT infection prevalence, which, therefore, should be interpreted with caution. However, it is felt that the identification of correlates of MT infection has not been greatly influenced by a possible recruitment bias. The relatively low rate of prisoners completing testing reflects a common problem of clinical practice in this setting. In fact, it is well known that a high proportion of detained persons often do not complete the diagnostic and therapeutic procedures aimed at the control of TB or other health problems $[26,28,38]$. This is due to a number of factors, but mainly to inmate release or to their relocation to other prisons before a programmed health assessment can be completed. Resolution of this problem requires a more adequate coordination between the necessity for security measures and the health needs of prisoners, between the health services of different correctional facilities and, lastly, between the prison health services, community care centres and public health agencies [22, 39].

Another possible bias in the current results might be represented by the absence of information concerning previous bacille Calmette-Guérin (BCG) vaccinations. In the current study, this information was not obtained, since both the patients' history in this regard and the search for the BCG scar are difficult and often unreliable [40,41]. However, if a previous BCG vaccination ever influenced the overall prevalence of positive TST, it is believed that this occurred only to a minor extent, and that this possible influence did not significantly affect the identification of the correlates of the MT infection. In fact, several recent studies found no significant effect of a previous BCG on TST results [42-44], since BCG reactivity disappears within years [44]. A metaanalysis on this topic showed that this reactivity becomes either very weak or absent within $15 \mathrm{yrs}$ of vaccination [45]. BCG was incorporated into the infant vaccination schedule by the Expanded Programme on Immunization in 1974 [42], but the coverage in many countries remained inadequate for $\geqslant 10$ yrs [46]. BCG was prescribed and administered at birth or within the fifth year of age in most countries [47]. In Italy, BCG became mandatory by law for certain risk groups and all military recruits starting in 1970, and was routinely performed up to 2002. The influence of BCG on TST results is low in subjects from countries with a high TB prevalence [42]. For all the previous reasons, if any influence of BCG on the current authors' TST was suspected, it would have led to an overestimation of the MT infection, mainly among the younger inmates and those born in Italy; even if this overestimation had been recognised, it would have strengthened, rather than weakened, the strong correlation found between TST reactivity and both older age and being foreign-born.

A TST positivity was detected in $17.9 \%$ of the current study population. Comparison with the general population is difficult, since no large TST surveys have ever been conducted in Italy. The data from Mantoux tests performed in 1996-1999 among 2,369 Italian military recruits showed a reaction size $>5 \mathrm{~mm}$ in $6.1 \%$ subjects and $>10 \mathrm{~mm}$ in $4 \%$ [48]. The current finding is similar to that reported by LовAто et al. [28] from 49 correctional facilities in the USA (mean TST positivity rate $=17 \%$ ). In Europe, as mentioned previously, data are available (not recent) from only two penitentiaries in Spain $[30,31]$, where a $56 \%$ rate of MT infection was detected. This extremely high prevalence, similar to that reported in developing countries such as Pakistan [29], was probably influenced by several factors, such as a lower cut-off for skin-test positivity ( $>5 \mathrm{~mm}$ induration in all inmates) than that used by LOBATO et al. [28] and in the current study, and a higher rate of TB infection and disease both in prisoners and the general community when the surveys were performed (1991-1994). Conversely, in the current study, different rates of TST positivity were reported from the participating centres (range $0-36.11 \%$ ). Also, the frequency of positive TST found in various correctional facilities within the USA ranged 12.5$30 \%$ [23-28]. This variation within the same geographic area can most probably be explained by the fact that the relative proportion of at-risk groups for MT infection can vary among different prisons, and, over time, even within the same facility. Therefore, based on these findings, inmates should not be considered merely as a single at-risk population for MT infection, but rather as an heterogeneous population composed of several, if not many, different subgroups, each with a specific risk. Periodic identification in a particular prison setting of those inmate groups at an increased risk of MT infection would help to "target" measures for TB control in that setting.

Male sex was found to be associated with TST positivity in univariate analysis $(\mathrm{OR}=22.3)$. It was not possible to verify this association, since females had to be excluded from the multivariate analysis. However, this finding is consistent with that reported in the two studies that addressed, thus far, this correlation between TST and sex [28, 31].

As reported in other surveys [29-31], age was one of the factors that strongly correlated with TST positivity in the current population. In the multivariate analysis, inmates $>30 \mathrm{yrs}$ showed a four-fold greater risk for MT infection compared with younger subjects. The reasons for this association can be attributed both to the increasing probability of exposure to MT with increasing age and to the greater diffusion of TB in the past [49].

A markedly higher rate of MT infection was observed among foreign subjects $(\mathrm{OR}=4.9 ; 95 \% \mathrm{CI}=2.40-9.97)$. The only study that examined this correlation in a prison setting was from the USA [27], reporting similar results (foreign-born inmates were 5.9-times more likely to have positive TST than USA-born inmates). In the current study population, inmates from Eastern Europe showed the highest frequency of test positivity 
(37.9\%), which is statistically similar to the results in subjects from other low-income areas (table 2). Detainees from all these areas showed a 3.4-4.4-fold greater risk of being MT infected compared with residents born in Italy and other Western European countries. These findings are consistent with the high proportion of new TB cases represented by foreign subjects, reported among the general population in Italy and other industrialised countries [50,51]. Moreover, the present result is quite distressing, since there is a much higher concentration of immigrants in Italian prisons (up to 64\%) than in the community (2.5\%) [33]. This can be partly explained by the geographical position of Italy, representing a major gateway for both legal and illegal immigration into Western Europe from the many low-income areas facing the Mediterranean Sea. No significant correlation was found in the foreign population between TST positivity and the time of arrival in Italy, suggesting that MT infection in these subjects is mainly acquired in the country of origin, i.e. before immigration, even though TB usually develops after arrival at the destination [50].

According to multivariate analysis, an education of $\leqslant 5$ yrs correlated (weakly) with a positive TST, whereas living conditions of $\geqslant 3$ persons per room before incarceration showed no association. These findings correspond with those reported by the only survey considering these variables in a confined population [29], suggesting that a low educational level can be a more reliable indicator than a crowded living condition as a indication of poor socio-economic status, which is a well-known risk factor for MT infection [35, 52].

In the current study population, the risk of being reactive to TST increased with the duration of current detention $(11 \%$ increased risk for each year spent in prison with multivariate analysis). This result is in agreement with results from other reports examining this correlation [18, 29, 31], and suggests that, in Italy, as elsewhere, prisons represent a risk environment for MT transmission. Conversely, the above-mentioned surveys performed in the Italian prison system in 1994 [32] showed that $26.1 \%$ of TB cases were due to an exposure that occurred during detention. The most probable reasons for this risk have been previously mentioned.

With univariate, but not multivariate, analysis, HIV-infected inmates showed a lower rate of positive TST than those who were HIV negative. A negative correlation between the two variables was also detected in two previous studies [30, 31], whereas only one survey [27] reported a positive correlation with univariate analysis, but only $15 \%$ of that population was HIV tested. The frequency of positive Mantoux testing in HIVinfected subjects is often influenced by the high rate of false negatives documented in these subjects [36] and can be misleading, considering the higher risk in the same population for both MT infection and active disease [35, 36]. Therefore, among HIV-infected subjects, active surveillance, early diagnosis and proper management of TB represent measures deemed necessary, regardless of TST results, for the control of the spread of MT infection and disease.

Whether IDUs are at an increased risk for MT infection is a controversial topic $[35,53]$. In the present study, no association was found between TST positivity and IDUs, in agreement with the only two studies investigating this correlation in a prison setting $[30,31]$. This result, however, might have been influenced by several factors: in particular, these subjects were generally young with elevated rates of HIV infection, two conditions that favour TST negativity.

In conclusion, the current study indicates that subjects detained in the Italian prison system are affected by a relevant rate of MT infection and are at risk for MT transmission. Therefore, the current recommendations concerning populations at high risk for $\mathrm{TB}$, and specifically those within the detention system $[1,36,54]$, should be fortified nationwide. In particular, the screening of entrants and the clinical surveillance of residents is very important in order to obtain a prompt diagnosis, isolation and treatment of inmates with $\mathrm{TB}$, thus avoiding undiagnosed smear-positive cases. Furthermore, TST screening is helpful to identify and treat latent MT infection. Control measures should be aimed especially at groups with a greater risk for MT infection, such as males $>30 \mathrm{yrs}$, immigrants, subjects with an education $\leqslant 5$ yrs or those who are detained $>2$ yrs. In addition, TB-control measures need to be provided for all HIV-infected persons, regardless of TST results. This is necessary to prevent the spread of MT among detainees, staff and, ultimately, the surrounding community $[1,21,22,27,37]$.

Conversely, the higher concentration of groups at risk for Mycobacterium tuberculosis infection in this setting, compared with the general population, provides an ideal opportunity to focus public health efforts concerning tuberculosis control in these subjects, who are otherwise often difficult to reach in the community, thus ultimately providing benefits for the entire society.

\section{ACKNOWLEDGEMENTS}

Participants of the GLIP (Gruppo di Lavoro Infettivologi Penitenziari) are as follows. Members who recruited into the study patients with questionnaire data and results of tuberculin skin testing, serologic tests and chest radiographs: A. Sardu (Casa Circondariale Femminile (female jail), Pozzuoli, Napoli), G. Quercia (Casa di Reclusione (prison), Sulmona AQ), S. Vullo (Casa Circondariale (jail), Agrigento), A. Casti (Casa Circondariale and Casa di Reclusione, Cagliari), S. Novati (Casa di Reclusione, Milano Opera), G. Mazzarello (Casa Circondariale, Genova), M. Dierna (Casa Circondariale, Ragusa). Members who recruited patients with questionnaire data and serological tests only: A. Romano (Casa Circondariale, Lecce), V. Iovinella (Casa Circondariale and Casa di Reclusione, Napoli Poggioreale), G. Florenzano (Casa Circondariale, Sassari).

The authors are grateful to P. Butts for assistance in the preparation of the manuscript.

\section{REFERENCES}

1 World Health Organization. Tuberculosis control in prisons. A Manual for Programme Managers. WHO/CDS/TB/ 2000.281. Geneva, World Health Organization, 2000.

2 Stead WW. Undetected tuberculosis in prison. Source of infection for the community at large. JAMA 1978; 240: 2544-2547. 
3 Jones TF, Craig AS, Valway SE, Woodley CL, Schaffner W. Transmission of tuberculosis in a jail. Ann Intern Med 1999; 131: 557-563.

4 Centers for Disease Control and Prevention. Tuberculosis outbreaks in prison housing units for HIV-infected inmates: California, 1995-1996. MMWR Morb Mortal Wkly Rep 1999; 48: 79-82.

5 McLaughlin SI, Spradling P, Drociuk D, Ridzon R, Pozsik CJ, Onorato I. Extensive transmission of Mycobacterium tuberculosis among congregated, HIVinfected prison inmates in South Carolina, United States. Int J Tuberc Lung Dis 2003; 7: 665-672.

6 Jochem K, Tannenbaum TN, Menzies D. Prevalence of tuberculin skin test reactions among prison workers. Can J Public Health 1997; 88: 202-206.

7 Steenland K, Levine AJ, Sieber K, Schulte P, Aziz D. Incidence of tuberculosis infection among New York State prison employees. Am J Public Health 1997; 87: 2012-2014.

8 Cone JE, Harrison R, Katz E, Chan J, Dewsnup D, Osorio AM. Tuberculosis transmission to prison employees during an outbreak among prisoners at two California prisons. J Healthcare Safety 2000; 4: 75-79.

9 Centers for Disease Control and Prevention. Tuberculosis transmission in multiple correctional facilities: Kansas, 2002-2003. MMWR Morb Mortal Wkly Rep 2004; 53: 734-738.

10 Jones TF, Craig AS, Valway SE, Woodley CL, Schaffner W. Transmission of tuberculosis in a jail. Ann Intern Med 1999; 131: 557-563.

11 Fernandez de la Hoz K, Inigo J, Fernandez-Martin JI, et al. The influence of HIV infection and imprisonment on dissemination of Mycobacterium tuberculosis in a large Spanish city. Int J Tuberc Lung Dis 2001; 5: 696-702.

12 World Health Organization. Tuberculosis in prisons. http://www.who.int/tb/dots/prisons/story_1/en. Date last accessed: March 7 2004. Date last updated: January 2005.

13 Valway SE, Greifinger RB, Papania M, et al. Multidrugresistant tuberculosis in the New York State prison system, 1990-1991. J Infect Dis 1994; 170: 151-156.

14 Spradling P, Nemtsova E, Aptekar T, et al. Anti-tuberculosis drug resistance in community and prison patients, Orel Oblast, Russian Federation. Int J Tuberc Lung Dis 2002; 6: 757-762.

15 Pleumpanupat W, Jittimanee S, Akarasewi $\mathrm{P}$, et al. Resistance to anti-tuberculosis drugs among smear-positive cases in Thai prisons 2 years after the implementation of the DOTS strategy. Int J Tuberc Lung Dis 2003; 7: 472-477.

16 Toungoussova OS, Mariandyshev A, Bjune G, Sandven P, Caugant DA. Molecular epidemiology and drug resistance of Mycobacterium tuberculosis isolates in the Archangel prison in Russia: predominance of the W-Beijing clone family. Clin Infect Dis 2003; 37: 665-672.

17 Reyes H, Coninx R. Pitfalls of tuberculosis programmes in prisons. BMJ 1997; 315: 1447-1450.

18 Bellin EY, Fletcher DD, Safyer SM. Association of tuberculosis infection with increased time in or admission to the New York City jail system. JAMA 1993; 269: 2228-2231.

19 Coninx R, Eshaya-Chauvin B, Reyes H. Tuberculosis in prisons. Lancet 1995; 346: 1238-1239.
20 MacIntyre CR, Kendig N, Kummer L, Birago S, Graham NM. Impact of tuberculosis control measures and crowding on the incidence of tuberculous infection in Maryland prisons. Clin Infect Dis 1997; 24: 1060-1067.

21 Hammet TM, Gaiter JL, Crawford C. Reaching seriously atrisk populations: health interventions in criminal justice settings. Health Educ Behav 1998; 25: 99-120.

22 Coninx R, Maher D, Reyes H, Grzemska M. Tuberculosis in prisons in countries with high prevalence. BMJ 2000; 320: 440-442.

23 Anderson KM, Keith EP, Norsted SW. Tuberculosis screening in Washington state male correctional facilities. Chest 1986; 89: 817-821.

24 Pelletier AR, DiFerdinando GT Jr, Greenberg AJ, et al. Tuberculosis in a correctional facility. Arch Intern Med 1993; 153: 2692-2695.

25 Koo DT, Baron RC, Rutherford GW. Transmission of Mycobacterium tuberculosis in a California State Prison, 1991. Am J Public Health 1997; 87: 279-282.

26 Tulsky JP, White MC, Dawson C, Hoynes TM, Goldenson J, Schecter G. Screening for tuberculosis in jail and clinic follow-up after release. Am J Public Health 1998; 88: 223-226.

27 Saunders DL, Olive DM, Wallace SB, Lacy D, Leyba R, Kendig NE. Tuberculosis screening in the federal prison system: an opportunity to treat and prevent tuberculosis in foreign-born populations. Public Health Rep 2001; 116: 210-218.

28 Lobato MN, Leary LS, Simone PM. Treatment for latent TB in correctional facilities: a challenge for TB elimination. Am J Prev Med 2003; 24: 249-253.

29 Hussain H, Akhtar S, Nanan D. Prevalence of and risk factors associated with Mycobacterium tuberculosis infection in prisoners, North West Frontier Province, Pakistan. Int J Epidemiol 2003; 32: 794-799.

30 Martin V, Gonzalez P, Cayla JA, et al. Case-finding of pulmonary tuberculosis on admission to a penitentiary centre. Tuber Lung Dis 1994; 75: 49-53.

31 Martin Sanchez V, Alvarez-Guisasola F, Caylà JA, Alvarez JL. Predictive factors of Mycobacterium tuberculosis infection and pulmonary tuberculosis in prisoners. Int $J$ Epidemiol 1995; 24: 630-636.

32 Starnini G, Lepri F, Squarcione S, Brunetti B, Gruppo di lavoro sulla TBC negli Istituti Penitenziari. Linee guida per la gestione della tubercolosi nelle carceri italiane [Working group on TB in Correctional Facilities. Guidelines for the management of tuberculosis in Italian prisons]. Bollettino per le farmacodipendenze e l'alcolismo 1997; 3: 32-37.

33 Ministerodella giustizia, Dipartimento dell'Amministrazione Penitenziaria, Ufficio per lo Sviluppo e la Gestione del Sistema Informativo Automatizzato, Sezione statistica. Rilevazione semestrale tossicodipendenza e infezione da HIV negli Istituti penitenziari [Biannual assessment of drug addiction and HIV infection in the correctional institutes]. Rome, Dept of Correctional Facilities, Ministry of Justice, 2003; pp. 5-57.

34 Istituto Superiore di Sanità. Aggiornamento dei casi di AIDS notificati in Italia al 31 dicembre 2002 [The National Institute of Health. Update of AIDS cases notified in Italy, 2002]. Notiziario dell'Istituto Superiore di Sanità 2003; 16: Suppl. 1, 1-14. 
35 Centers for Disease Control and Prevention. Core curriculum on tuberculosis. Atlanta, Centers for Disease Control and Prevention, 2000.

36 American Thoracic Society. Targeted tuberculin testing and treatment of latent tuberculosis infection. MMWR Recomm Rep 2000; 49: 1-51.

37 Hammett TM, Harmon MP, Rhodes W. The burden of infectious disease among inmates of and releases from US correctional facilities, 1997. Am J Public Health 2002; 92: 1789-1794.

38 White MC, Tulsky JP, Goldenson J, Portillo CJ, Kawamura M, Menendez E. Randomized controlled trial of interventions to improve follow-up for latent tuberculosis infection after release from jail. Arch Intern Med 2002; 162: 1044-1050.

39 Conklin TJ, Lincoln T, Flanigan TP. A public health model to connect correctional health care with communities. Am J Public Health 1988; 88: 1249-1250.

40 World Heath Organization. Immunological Basis for Immunization/Module 5: Tuberculosis. WHO/EPI/ GEN/93.15. Geneva, World Health Organization, 1993.

41 Fine PEM, Ponnighaus JM, Maine NP. The distribution and implications of BCG scars in Northern Malawi. Bull World Health Organ 1989; 67: 35-42.

42 Hizel K, Maral I, Karakus R, Aktas F. The influence of BCG immunisation on tuberculin reactivity and booster effect in adults in a country with a high prevalence of tuberculosis. Clin Microbiol Infect 2004; 10: 980-983.

43 Bowerman RJ. Tuberculin skin testing in BCG-vaccinated populations of adults and children at high risk for tuberculosis in Taiwan. Int J Tuberc Lung Dis 2004; 8: 1228-1233.

44 Al Zahrani K, Al Jahdali H, Menzies D. Does size matter? Utility of size of tuberculin reactions for the diagnosis of mycobacterial disease. Am J Respir Crit Care Med 2000; 162: 1419-1422.
45 Wang L, Turner MO, Elwood RK, Schulzer M, FitzGerald RK. A meta-analysis of the effect of Bacille Calmette Guérin vaccination on tuberculin skin test measurements. Thorax 2002; 57: 804-809.

46 WHO-UNICEF. Estimates of BCG coverage 1980-2003. http:/ /www.who.int/vaccines/globalsummary/timeseries / tswucoveragebcg.htm. Date last accessed: March 82005.

47 World Health Organization. Issues relating to the use of BCG in immunization programmes. A discussion document. WHO/V\&B/99.23. http://www.who.int/ vaccines-documents/DocsPDF99/www9943.pdf. Date last accessed: March 82005.

48 D'Amelio R, Stroffolini T, Biselli R, et al. Tuberculin skin reactivity in Italian military recruits tested in 1996-1997. Eur J Clin Microbiol Infect Dis 2000; 19: 200-204.

49 Dutt AK, Stead WW. Tuberculosis in the elderly. Med Clin North Am 1993; 77: 1353-1368.

50 Codecasa LR, Porretta AD, Gori A, et al. Tuberculosis among immigrants from developing countries in the province of Milan, 1993-1996. Int J Tuberc Lung Dis 1999; 3: 589-595.

51 EuroTB (InVS/KNCV) and the national coordinators for tuberculosis surveillance in the WHO European Region. Surveillance of tuberculosis in Europe. Report on tuberculosis cases notified in 2001. Saint-Maurice, Institut de veille sanitaire, 2003.

52 Cantwell MF, McKenna MT, McCray E, Onorato IM. Tuberculosis and race/ethnicity in the United States: impact of socioeconomic status. Am J Respir Crit Care Med 1998; 157: 1016-1020.

53 Reichman LB, Felton CP, Edsall JR. Drug dependence: a possible new risk factor for tuberculosis disease. Arch Intern Med 1979; 139: 337-339.

54 Centers for Disease Control and Prevention. Prevention and control of tuberculosis in correctional facilities. MMWR Morb Mort Wkly Rep 1996; 45: 6-14. 